\title{
COEFFICIENT OF FRICTION OF FABRICS
}

\author{
By Alfred A. Mercier ${ }^{1}$
}

\section{ABSTRACT}

This paper describes a simple method for specifying the slipperiness of fabrics, by measurement of the coefficient of friction between two pieces of the same material. A block covered with a sample of the fabric to be tested is placed on an inclined plane which is covered with another piece of the same fabric. The angle between the inclined plane and the horizontal is then increased to a value at which the block just begins to slide. Owing to a rearrangement of the fibers in the surfaces of the fabric this minimum angle decreases with successive slides. A number of slides are, therefore, made until a constant limiting angle is found. The tangent of this limiting angle is defined as the coefficient of friction for the fabric. Some applications of this measurement are mentioned, and illustrative results are given.

\section{CONTENTS}

I. Introduction

II. Coefficient of friction

III. Apparatus _...

IV. Test procedure

V. Illustrative results

\section{INTRODUCTION}

The utility of fabrics for certain purposes depends to a large degree on their surface characteristics. For example, slipperiness is undesirable in the backing of rugs but is required of linings used in coat sleeves, shoes, and jewelry cases, and is a prominent feature of sleeping garments. The "creeping" of garments over one another, particularly the creeping of some underwear, is an objectionable feature which is related to the slipperiness or smoothness of the surface.

The surface characteristics vary with $(a)$ the material (cotton, wool, silk, or rayon), (b) the construction of the yarn (hard or soft), (c) the weave (square, twill, or fancy), and $(d)$ the finish. A smooth surface is more slippery than a napped surface. The creeping of a garment is noticeable when the fabric of which it is made is nearly of the same weight, but of different surface texture from the fabric with which it is in contact. The lighter of the two fabrics will creep up on the heavier one unless the former has a more slippery surface. Wool garments do not tend to creep because their weight is usually greater than the weight of the adjacent undergarment.

The present paper describes a simple method for specifying the slipperiness or smoothness of a fabric in terms of the coefficient of static friction between two pieces of the same material. The work was done in connection with the fine fabric investigations of the Cotton-Textile Institute and the Bureau of Standards. 


\section{COEFFICIENT OF FRICTION}

When a rectangular block is placed on an inclined plane, as in Figure 1, its tendency to slip under the pull of gravity is opposed by the friction between its lower surface and the surface of the plane. The weight of the block $(W)$ exerts a force $(N)$ normal to the inclined plane and a force $(F)$ parallel to this plane. The frictional force $\left(F^{\prime}\right)$ resists the slipping tendency due to $\left(F^{\prime}\right)$. If the angle between the inclined and horizontal planes is increased $\left(F^{\prime}\right)$ becomes greater and $(N)$ smaller. Until $(F)$ exceeds a certain value the block will not slide.

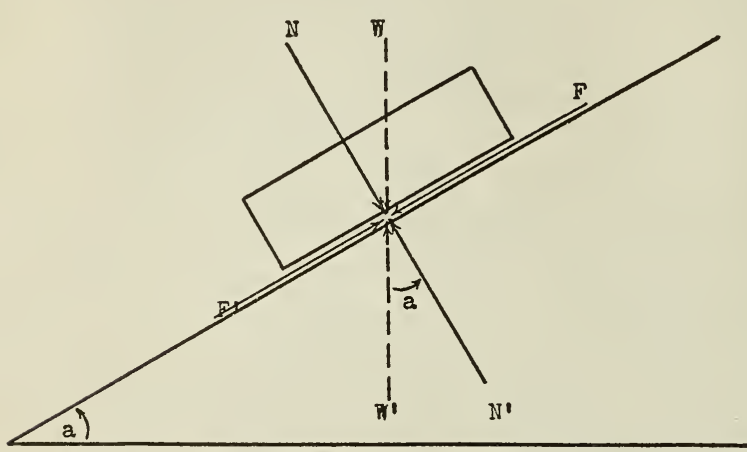

FigURE 1.-Diagram of forces on inclined plane When the value of the angle $(a)$ is such that the force $(F)$ equals the frictional force $\left(F^{\prime}\right)$ slipping is impending and the ratio of the limiting frictional force $\left(F^{\prime}\right)$ to the normal force $\left(N^{\prime}\right)$ is called the coefficient of static friction between the block and the plane. From the geometry of the figure the ratio can be shown

to be the tangent of the angle $(a)$. Thus

and

$$
\begin{aligned}
& F^{\prime}=W^{\prime} \sin a \\
& N^{\prime}=W^{\prime} \cos a
\end{aligned}
$$

$$
\text { coefficient of friction }=f=\frac{F^{\prime}}{N^{\prime}}=\frac{W^{\prime} \sin a}{W^{\prime} \cos a}=\tan a
$$

The result obtained when the block and the inclined plane are both covered. with the same fabric is the coefficient of friction for this fabric on itself.

The coefficient of friction is independent of the area of the surfaces in contact, and is also independent of the weight of the block, providing the pressure of one surface on the other does not modify the original surface characteristics of the fabric. The coefficient of friction depends on the smoothness of the surfaces in contact and on the presence of a lubricant, such as oil or other finishing materials between the surfaces.

\section{APPARATUS}

A photograph of the apparatus is shown in Figure 2. Two boards, each 22 inches long and 6 inches wide, are hinged together at one end. One of the boards rests on three small supports which can be adjusted to bring the board to a horizontal position. The angle between the boards can be changed by a screw arrangement, and this angle or its tangent read on a scale on the upper surface of the horizontal board. The block of wood, 8 inches long and 6 inches wide, weighs about $11 / 4$ pounds. This block and the inclined plane are covered with the fabric to be tested. Clamps for holding the fabric on the block and on 
B. S. Journal of Research. RP196

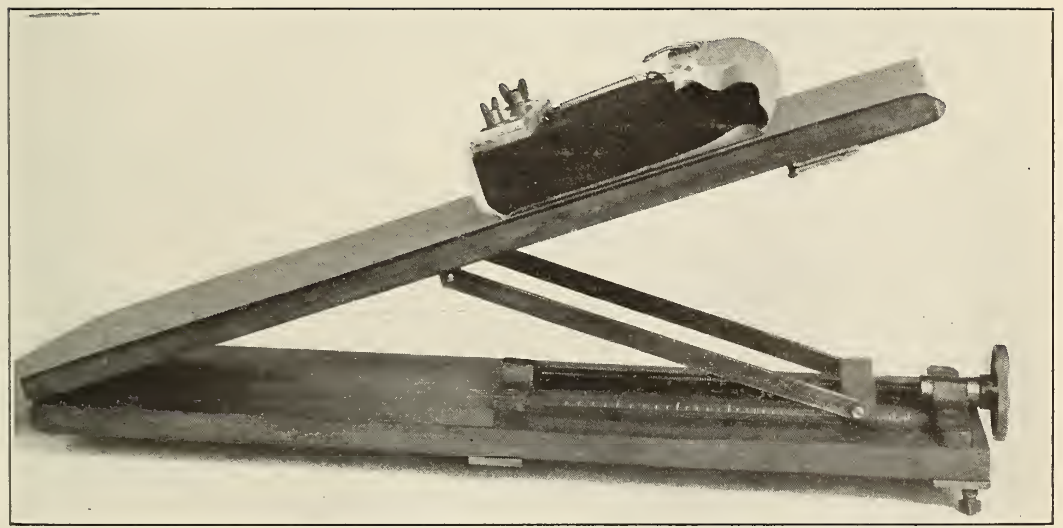

Figure 2.-Device for measuring coefficient of friction between fabrics 
the inclined plane are shown in the figure. A spring keeps the fabric under tension on the block and a small weight clamped to the lower end of the fabric keeps the fabric taut on the inclined plane during the test.

\section{TEST PROCEDURE}

The covered block is placed on the inclined plane and the plane is raised to a point where, with the assistance of light tappings on the board, the block begins to slide. The sliding angle is noted and the plane is lowered several degrees. The block is again placed on the inclined plane and the above procedure then repeated several times.

For some fabrics the angle between the planes, for the first few slides will decrease one or more degrees with each slide because of a rear-

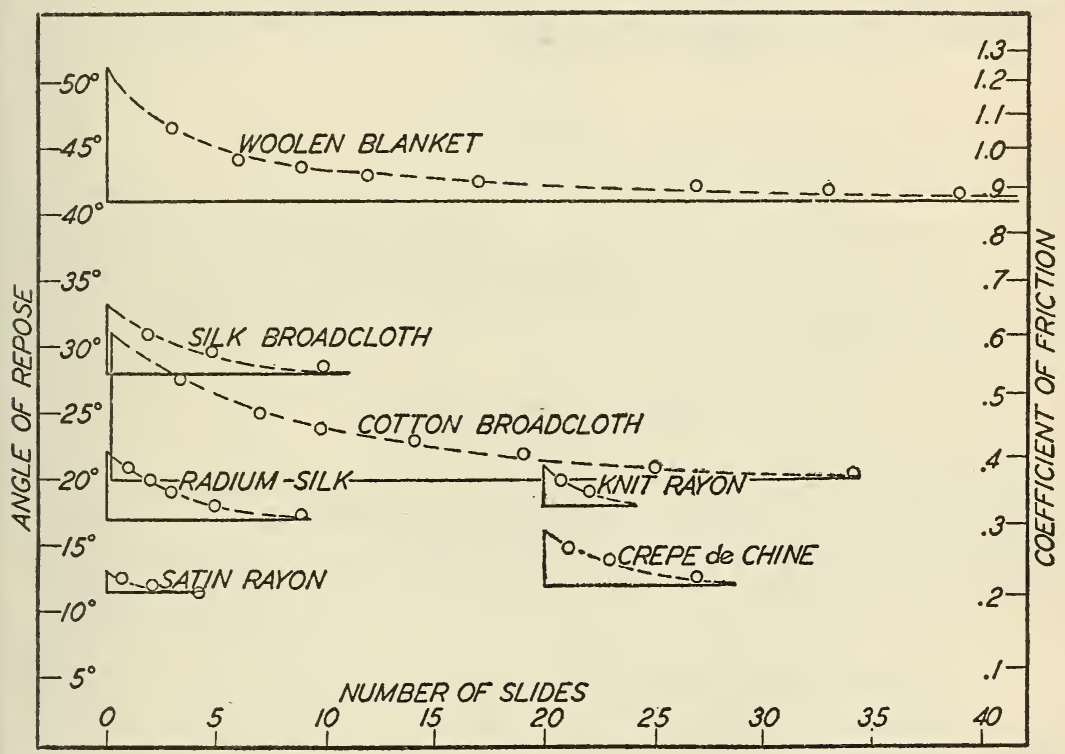

FIGURE 3.-Angles of repose and coefficient of static friction after successive slidings of fabric on fabric

rangement of the fibers. As the surface gradually approaches a constant condition, the angle of inclination approaches a constant value. The tangent of this limiting angle is taken as the coefficient of friction for the particular fabric under test.

The decrease in the coefficient of friction, from its initial value for the first slide to its final value for the limiting angle, may be taken as an indication of the texture of the fabric. This is illustrated by fabrics whose fibers have a tendency to extend above the surface. Thus fabrics with short fibers and napped surfaces show greater changes in the coefficient of friction than fabrics with a smooth finish. The coefficient of friction for a fabric with a smooth surface is less than that for a fabric with a napped surface. 


\section{ILLUSTRATIVE RESULTS}

The results of tests on a variety of fabrics are shown in Figure 3. Angles between the two planes may be read at the left of the diagram and the coefficient of friction at the right. In every case the slide was made in the warp direction of both specimens. The results shown are for fabrics of different materials and weaves so that the position of each material on the diagram does not indicate the position that would be occupied by another fabric made from the same material, but of different weave. The results show that variations in the coefficient of friction of fabrics can be recorded with the apparatus herein described. The results also indicate that a complete study of the slipperiness of fabrics would include the effect of weaves, yarns, and finishes for each material.

Washington, February 24, 1930. 